\title{
Last and least
}

Findings on intrahousehold undernutrition from participatory research in South Asia

Erin C Lentz, Sudha Narayanan, Anuradha De

Indira Gandhi Institute of Development Research, Mumbai February 2019 


\title{
Last and least \\ Findings on intrahousehold undernutrition from participatory research in South Asia
}

\author{
Erin C Lentz, Sudha Narayanan, Anuradha De
}

Email(corresponding author): erinclentz@utexas.edu

\begin{abstract}
In this paper, we analyze intrahousehold mechanisms that rural South Asian women themselves identify as contributing to their inabilities to achieve adequate nutrition. The majority of our female respondents explain that, within their families, they are most likely to eat least and last and to seek lower quality healthcare later, both of which can lead to undernutrition. We consider the explanations that women provide for why they do so. In addition to norm abidance, we highlight two social factors: a partner's heavy alcohol use and intimate partner violence. Women report that these factors adversely impact their own health and food security status and potentially contribute to differential nutritional outcomes within the same household. The emic perspectives presented here show us: (1) many rural South Asian women report shouldering a relatively greater share of food and nutrition insecurity within their households, and (2) taking their perspectives seriously assists in identifying the underlying contributors to intrahousehold differences. These findings indicate the value a gendered perspective on both the drivers of and measurement of undernutrition. Attending to these intrahousehold factors in future quantitative research may provide important insights for understanding drivers of nutritional outcomes.
\end{abstract}

Keywords: Gender; intrahousehold; South Asia; nutrition; alcohol; intimate partner violence

JEL Code: J16, D13, I00, I3 


\title{
Last and least \\ Findings on intrahousehold undernutrition from participatory research in South Asia1
}

\author{
Erin C Lentz, Sudha Narayanan, Anuradha De ${ }^{2}$
}

\begin{abstract}
In this paper, we analyze intrahousehold mechanisms that rural South Asian women themselves identify as contributing to their inabilities to achieve adequate nutrition. The majority of our female respondents explain that, within their families, they are most likely to eat least and last and to seek lower quality healthcare later, both of which can lead to undernutrition. We consider the explanations that women provide for why they do so. In addition to norm abidance, we highlight two social factors: a partner's heavy alcohol use and intimate partner violence. Women report that these factors adversely impact their own health and food security status and potentially contribute to differential nutritional outcomes within the same household. The emic perspectives presented here show us: (1) many rural South Asian women report shouldering a relatively greater share of food and nutrition insecurity within their households, and (2) taking their perspectives seriously assists in identifying the underlying contributors to intrahousehold differences. These findings indicate the value a gendered perspective on both the drivers of and measurement of undernutrition. Attending to these intrahousehold factors in future quantitative research may provide important insights for understanding drivers of nutritional outcomes.
\end{abstract}

Keywords: gender; intrahousehold; South Asia; nutrition; alcohol; intimate partner violence

\footnotetext{
${ }^{1}$ Acknowledgements: Nirali Bakhla, Sweta Bhusan, Jason Cons, Anomita Goswami, Khushi Kabeer, Bharati Kulkarni, Ankita Mondal, Rezanur Rose Rahman, Krushna Ranaware, Udayan Rathore, and Sabarmati helped with data collection and analysis, and provided valuable insights. Civil society organizations Agragamee, Anwesha, Pradhan, and Sambhav in Odisha India and Nijera Kori in Bangladesh and their members generously participated in data collection. Participants at the 2017 ANH Academy Week, Kathmandu Nepal, provided helpful feedback. Funding was provided by the UK Department for International Development's Innovative Methods and Metrics for Agriculture and Nutrition Actions program (1.44), funded by UK taxpayers.

${ }^{2}$ Lentz is Assistant Professor at the Lyndon B Johnson School of Public Affairs, University of Texas, Austin, USA; Narayanan is Associate Professor, Indira Gandhi Institute of Development Research (IGIDR), Mumbai, India; De is director of Collaborative Research and Dissemination (CORD), New Delhi, India. Lentz is corresponding author: erinclentz@utexas.edu
} 


\section{Last and least \\ Findings on intrahousehold undernutrition \\ from participatory research in South Asia}

\section{Introduction}

In this paper, we analyze qualitative interviews with rural South Asian women to better understand social factors that contribute to undernutrition. The majority of our Bangladeshi and Odia female respondents describe intrahousehold inequities that hinder their abilities to achieve adequate nutrition. They explain that compared to other household members, and especially compared to their partners, they are generally more likely to cut back on or forego food and healthcare, basic requirements for adequate nutritional status (UNICEF 1990). Analysis of respondents' explanations about why these intrahousehold differences exist highlights not only social norms but also two social issues: a partner's heavy alcohol use and intimate partner violence (IPV). Women describe how these issues mediate who has access to and can make use of food and healthcare, constraining their abilities to secure adequate nutrition for themselves and often for other family members. Young women living in impoverished households, in particular, describe bearing the brunt of inadequate resources within households.

Attending to the social issues of IPV and alcohol use can help to better understand the drivers of intrahousehold nutritional outcomes. Quantitative models have identified a series of important factors, such as sanitation, heath policy, women's empowerment, and income, among others, that are associated with children's nutritional status in South Asia, which while decreasing, remains high (Headey et al. 2015; Coffey 2015). Yet, the explanatory power of such models, as measured by Rsquared, is often around thirty percent, meaning quantitative studies explain about one-third of the variation in nutritional status (Headey et al. 2015; Headey et al. 2017; D'Souza and Tandon 2018). Thus, there is much variation left for models to explain; further, fewer models focus on women's nutritional outcomes. Our findings suggest increased attention on social factors such as IPV and 
alcohol use and accurate inclusion of them in future quantitative work could help researchers better understand both the drivers of nutritional outcomes in general and of intrahousehold nutritional differences. Further, while addressing poverty may alleviate some intrahousehold inequity, this is not always the case. Interventions that take a holistic approach to address poverty along with IPV and heavy alcohol use may be more successful at reducing intrahousehold inequities in nutritional outcomes than focusing on poverty alone.

After a brief review of well-understood drivers of (primarily child) nutrition in South Asia, we introduce our framework for analyzing nutritional outcomes of women. We then describe our community-research methodology and data. We collected data from over two hundred and fifty women and men in rural Odisha, India and rural north-western Bangladesh. ${ }^{3}$ Using UNICEF's (1990, 2018) framework for understanding undernutrition as a guide, we present qualitative findings. First, we briefly show that several women in our sample present explanations consistent with prevailing norms and beliefs (i.e., norm-abidance) as a reason for intrahousehold food intake and healthcare inequities. Second, we focus on how a partner's alcohol use shapes some women's food intake and health decisions. Third, we consider the role of IPV in nutrition. We note that, especially in Odisha, disentangling alcohol use and IPV can be complex. We also consider how the strength of these social factors varies by women's roles within a household.

We conclude with next steps, arguing for the value of understanding household dynamics to support women and their families to fully realize their right to food and adequate nutrition. The emic perspectives presented here show us (1) many rural South Asian women report shouldering a greater share of food and nutrition security within households than other members, and (2) taking their perspectives seriously assists in identifying the underlying contributors to intrahousehold

\footnotetext{
${ }^{3}$ For expository ease, we refer to north-western Bangladesh as Bangladesh and Odisha, India as Odisha.
} 
differences, especially those that may not be fully resolved by addressing poverty. Women living with partners who are heavy alcohol users and or who use or threaten violence navigate these relationships in ways that shape their choices about food intake and health seeking behaviors. Future food and nutrition interventions could benefit from recognizing that women consider these factors when making decisions about their own nutritional status. These findings indicate the value of a gendered perspective on the both the drivers of and measurement of undernutrition.

\section{Factors contributing to child undernutrition in South Asia}

Much of what we know about drivers of undernutrition in South Asia comes from studies of children. The UNICEF framework $(1990,2018)$ articulates the drivers of child undernutrition and differentiates between immediate, underlying, and basic causes of poor nutrition. See Figure 1. Immediate causes include health, access to food, and infant and young child feed practices and behaviors. Underlying causes include food security, feeding and caregiving resources, and access to and use of health services, clean water and sanitation. Basic causes include the social, economic and political context and lack of financial, human, physical, social and natural capital. The framework often guides selection of factors in quantitative analyses (e.g., Headey 2012). Quantitative work draws on these immediate, underlying, and basic factors to understand what has contributed to recent improvements in child nutrition in South Asia and into variation in child stunting between India and Bangladesh (Headey 2012; Headey et al. 2015; Coffey 2015; Gillespie et al. 2017; Kohli et al. 2017; Nisbett et al. 2017).

Numerous studies examine the roles of basic causes of undernutrition, which can range from government programs to economic growth to social norms to technology. In South Asia, nutritional programs, health insurance, and access to health services have improved nutritional outcomes (Gillespie et al. 2017; Kohli et al. 2017; Nisbett et al. 2017). Economic growth can support better 
nutrition, albeit the effect varies (Headey 2012) and households with adequate income may still have undernourished members (Avula et al. 2016). In South Asia, gender-related social norms including mother's early marriage, early pregnancy (Coffey 2015), and position within a joint family (Coffey et al. 2017) and children's gender (i.e., son preference) (Raj et al. 2015), birth order and birth interval (Headey et al. 2015), preferential food allocation (Munro and McIntyre 2014) all influence children's nutritional outcomes. Women's empowerment has also been linked to improved child nutrition. Cunningham et al. (2015), in a review of articles on South Asia published between 1990 and 2012, find that women's empowerment is generally positively associated with child anthropometry, but results are mixed, in part because empowerment is measured in a variety of ways (see also Malapit et al. 2015; Pratley 2016). While research into the roles of women is crucial for understanding the nutritional achievements of their children, undernourishment and hunger of women (and men) matter in their own right.

\section{Intrahousehold variation in undernutrition in South Asia}

Children's nutritional status, the main research focus on nutrition in South Asia, may be an imperfect proxy for other household members. Research on intrahousehold bargaining models indicates that we should not presume that resources are equitably distributed within households (Alderman et al. 1995). Nor should we assume that nutritional achievements are equitably distributed within households (Haddad and Kanbur 1990; Marcoux 2002; Avula et al. 2016). An emergent literature has highlighted the limitations of relying on household level and child-level nutrition estimates. D’Souza and Tandon (2018) find that about a quarter of individuals are misclassified as adequately nourished, based on household level data, compared to individual level data. Lentz (2018) finds that some rural Bangladeshi women living in violent situations report eating less to avoid violence or to protect their children's nutritional status. Evidence from rural India suggests that, of the children whose nutritional status improved over time, a large proportion 
of them have mothers whose body mass index (BMI) declined (that is, women's nutritional status worsened) over the same period (Rampal and Narayanan 2018). In Odisha, women's BMI declined during 1998 and 2014 while children's nutritional status improved (Kohli et al. 2017).

Cultural practices, social context, and social norms are important drivers in nutritional outcomes in general (Bentley et al. 1999; Bezner Kerr et al. 2008; Pinstrup Andersen 2014; Kavle and Landry 2017; Nisbett et al. 2017) and could be important contributors to undernutrition for women, in particular. ${ }^{4}$ D'Souza and Tandon (2018) find that several measures of women's empowerment are associated with better nutritional outcomes relative to their partners, for women who are spouses of household heads in Bangladesh. Malapit et al. (2015) finds that women's empowerment is positively associated with both lower stunting rates in children and better maternal nutrition in Nepal. A potentially critical social norm influencing nutrition in South Asia is "patriarchal risk" (Cain et al. 1979). In rural South Asia, male family members are expected to provide for female relatives. Women without male relatives or women whose male relatives fail to provide for them face economic and social vulnerability. The threat of these vulnerabilities changes the incentives women face, encouraging them to abide by inequitable norms (Kabeer 2011). Women's contributions to the household may be undervalued, factors needed for women to achieve nutrition may be withheld, and women themselves may undermine their own nutritional status in order to maintain standing within a patriarchal structure.

Further, patriarchal relations extend to many aspects of rural South Asian women's lives, including food allocation and nutrition. Harriss-White (1991) argues, "food behaviour cannot usefully be abstracted from the social relations of patriarchy" (p. 38). Intrahousehold food inequities are

\footnotetext{
${ }^{4}$ Aside from research on empowerment, relatively few quantitative nutrition studies focus on social factors, perhaps in part because they are challenging to identify and measure (or convert into indicators for quantitative models). This is beginning to change; for example, the Pro-WEAI captures order of eating within households.
} 
amplified when households rely on coping strategies that lead to poor nutrition. The practice of women eating last and least means, effectively, that women are often presented with the least caloric and nutritious remainders of dinner (Lentz 2018). Harris-Fry et al. (2017) finds that the greatest inequities in food intake, with adult women eating least, "occurred in households experiencing severe or unexpected food insecurity" (p. 1). Pregnant women often eat less to have easier deliveries and many foods are taboo for women; further, women face different dietary restrictions and fasting norms than men (Sohoni 1998; Kavle and Landry 2017). Collectively, these findings suggest the value of analyzing factors that could lead to differential nutritional outcomes within the same household.

\section{Methodology}

\section{Community Based Research}

In each rural agrarian site (northwest Bangladesh, and rural hilly and coastal areas of Odisha in India), we employed qualitative, community-based research. We partnered with rural civil society members, drawn from the communities we aim to understand, and trained them in community research techniques. About $80 \%$ of the civil society members who were trained as community researchers were women. Over the course of several days, our researchers described the role of gender in mediating agriculture to nutrition linkages, how nutritional decisions are made in their families, and which aspects mattered most to them. Through this dialogue, we identified a variety of factors that influence nutrition that are both common in the literature (e.g., poverty, weak institutions, sanitation) and less common (e.g., common pool resources). Community researchers were then trained in semi-structured interview techniques, including to look for and ask follow-up questions when interviewing women about their lives. Researchers focused on decision-making and sources of tension within a household and asked for concrete examples. The training included protecting human subjects. 
After training, community researchers returned to their communities. ${ }^{5}$ Using audio-recorders, each researcher had one-on-one discussions with poor and marginalized (e.g., landless) communitymembers of the same gender. Each evening, we screened interviews to ensure that researchers abided by IRB standards. The length of interviews ranged from 20 minutes to 90 minutes; most were between 30 and 45 minutes.

Researchers engaged community members in interviews about decision-making, power, and nutritional practices in their households, including in the areas of meal preparation, agricultural production, use of common pool resources and other sources of income, child spacing and weaning, and health and water. The conversation topics related to issues that people face in their daily lives. For example, regarding decision-making, specific questions included: What nutritional decisions are you involved in? What roles do other household members play in these decisions? Why were these the decisions that were taken? Not all topics were discussed in each interview. Interviewers were trained to seek depth rather than breadth. This approach trades off direct comparability across structured interviews for a more wide-ranging responses that may be less discussed in the literature.

In Bangladesh, we partnered with Nijera Kori, a landless laborers' movement. Nijera Kori, which means "we do it ourselves", has partnered with researchers to both carry out community-based research and to use the findings in their own work (see Cons and Paprocki 2010; Lentz 2018). Over a five-day period at a training center in Bogra, 14 members of Nijera Kori were trained as community researchers. Ten community researchers ( 8 women and 2 men) conducted interviews

\footnotetext{
${ }^{5}$ Interviewers explained the project and sought informed consent prior to recording interviews, following human subjects guidelines from the University of Texas's Institutional Review Board (IRB), which also reviewed research protocols. Respondents were provided contact information with civil society staff, who operate within or nearby respondents' communities.
} 
with other members of their home communities, in Gaibanda and Rangpur districts, both in northern Bangladesh.

In Odisha, we partnered four different organizations in as many districts, Anwesha, Sambhav, Agragamee and PRADAN in the districts of Ganjam, Nayagarh, Raygada and Khandhmal respectively. While all four organizations worked with resource constrained communities, their specific focus and scale of operation was different. Anwesha establishes women's groups; Sambhav promotes organic farming; Agragamee focuses on sustainable development with rural tribal communities; PRADAN, a large development organization, implements interventions in a broad range of livelihood activities. We trained 19 women as community researchers for four sites over a span of four days.

The civil societies we partnered with draw their members from landless households in rural Bangladesh and from rural and impoverished communities in Odisha. Thus, the community researchers were drawn from the same marginalized groups and populations who they were interviewing. As insiders in their communities, community researchers have often experienced similar issues as the interviewees, making it easier for them to engage in frank discussions than when researchers "from away" talk to the extreme poor. For this reason, some of the interviews are very forthright about issues less commonly heard, including how excessive alcohol use and IPV influence nutrition. Further, the use of semi-structured interviews means that interviewees often spent the majority of the interview on topics that mattered most to them and provide a unique view into what issues matter to interviewees.

\section{Sample selection}


We selected our sites because their residents are likely to experience periodic food insecurity and most households in our sample were impoverished. ${ }^{6}$ Family structures across our sites included, among others, nuclear families, extended families where a son, his spouse and their children may live with his parents, single parents with children, and widowed parents or in-laws residing with their children.

In Bangladesh, we selected ten villages from Gaibanda and Rangpur districts, both of which regularly experience monga, seasonal hunger (Khandker et al. 2012). Most respondents are landless laborers or small scale farmers, primarily producing rice. Many describe experiences with poverty, hunger and food insecurity. Nearly all are Muslim. During May and June 2016, we collected 134 interviews; 24 of the interviews were with men. Community researchers used snowball sampling. We tracked basic demographic information on age, marital status, number of children, and wealth during the interview period. Toward the end of the fieldwork period, researchers purposively sampled additional community members who were not well-represented in our initial sample. ${ }^{7}$ About 25 percent of our sample were Nijera Kori members; about 65 percent described experiencing food and nutrition insecurity recently. Because we purposely conducted this research in a monga effected area, this rate may be higher than in other parts of rural Bangladesh. Interviews occurred after the boro rice harvest, in May, a time of year of relative plenty and less labor pressure. After reviewing all the interviews for recording quality, depth of the interview, and variation by demographic factors, we selected 35 interviews for translation and coding.

In Odisha, the sample was drawn from four districts representing diverse agro-ecological zones, and diverse caste and tribal groups. Selected communities have high rates of rural poverty,

\footnotetext{
6 Village names are suppressed, and pseudonyms are used for confidentiality.

7 While Nijera Kori members may have most affinity with poor and marginalized households, we ensured the sample included other households as well. Our analysis of the interviews does not indicate a greater willingness to respond or to provide detailed interviews by age, marital status, number of children, or wealth.
} 
reflecting that the dominant livelihoods are often precarious. In Ganjam district, most households engage in either fishing in the sea or selling fish in nearby urban centers. Others are from the marginalized castes, wage workers in agriculture, or casual laborers working in jobs such as making stone chips in nearby quarries. This area is prone to both cyclones and drought. Households in Rayagada district belong to tribal communities that are engaged in small scale upland farming, including jhuming (slash and burn) farming. Rayagada's households depend on the forests for fuel, fodder and food. In Kandhmal too, our sample comprised tribal households whose livelihoods depend on forests (e.g., making leaf plates and collecting forest foods). Many of them had recently obtained training to process turmeric and were also members of savings and credit groups. In Nayagarh, in the plains, households are comprised of smallholders or wage workers in agriculture. In total, during June and July of 2016, 183 women were interviewed; 170 interviews were translated..$^{8}$

\section{Analysis}

In our interviews, women described the current issues within their homes that hinder their and their families' abilities to achieve the nutrition they desire. ${ }^{9}$ We utilized the UNICEF Framework (figure 1), which we adapted for adults, to assess which factors were relevant to women's nutritional status. Our framework for adults parallels the UNICEF framework, which focuses on dietary intake, care, and health domains as underlying drivers of nutritional outcomes for children (Narayanan et al. under review). To adapt this figure for able-bodied adults, we removed care practices from the immediate drivers of undernutrition and focus on health and dietary intake as the underlying causes of (adult) nutrition.

\footnotetext{
8 Interviews that were not translated had poor sound quality or were of extremely short duration.

${ }^{9}$ Interviews were analyzed with Nvivo software. All co-authors were involved in identifying keywords for coding. One author and one research assistant coded; one author arbitrated to achieve reliability of codes. Codes are available on request.
} 


\section{Respondents' perspectives on contributors to intrahousehold food and health inequities}

While numerous factors contribute to undernutrition, we focus on respondents' explanations for intrahousehold differences in insufficient access to food and inadequate health services. In our sample, many women report eating last and or eating the least nutrient dense foods in both Odisha and Bangladesh, and report regularly experiencing hunger. Many women also report delaying healthcare expenditures and or seeking lower quality care. Ill health and inadequate food intake can have lasting nutritional and other health consequences (UNICEF 1990).

Many respondents explain that intrahousehold differences exist because of norms. Several more women explain that a partner's alcohol use and or IPV makes them less likely to push again these norms and thus shape their use of food and health services. These basic, social causes are less commonly studied than other drivers of insufficient access to food and inadequate health, such as poverty and freedom of movement. This is not meant to imply that such drivers of undernutrition are unimportant. Poverty, for example, limits the abilities of household members to circumvent various norms that contribute to undernutrition. Rather, we aim to identify less studied barriers that likely contribute to variation in nutritional outcomes within households, and in the case of a partner's heavy alcohol use, can also contribute to further impoverishment. Unless otherwise noted, the following interviews are with women.

\section{Norms around access to food and adequacy of health}

Many women are matter-of-fact that they eat last and least either because they believe it is the right thing to do or because they hope to avoid quarrels. In Bangladesh, Rani, a Hindu woman struggling to feed her husband and two teenage sons eats follows this norm. She explains "I'm a woman, it is okay for me to starve." A few respondents explained that they follow food allocation norms because other members within the family expected them to do so, including to the point of surveillance. In 
Odisha, Pritilata describes life shortly after her marriage. At that time her joint family did not trust that she was not taking extra food. She explains, "I would serve first to my husband because he was going to work, then to my father-in-law and old grand mother-in-law. Then I used to feed my young children. There after I would take my meal. Sometimes, my father-in-law would check the cooking pot to see whether I might have cooked more rice. If he saw some quantity rice in the pot, he would start to scold me that I had hidden rice for my own. I would bear it, cry and remain silent." In both of these cases, poverty contributes to the tension around food; however, poverty does not explain why women disproportionately sacrifice.

In households where women eat last, order of eating is often maintained even in times of seasonal food insecurity. Nearly all our Odia respondents reported eating last and least, and many described cutting back further during the lean season in order to maintain the wellbeing of other members. While women respondents report that their partners consume three meals a day throughout the year, women described needing to restrict their intake to two meals per day during the summer and rainy season. This finding - that women's nutritional status often deteriorates more than other members within the same household - has been observed elsewhere, including in the Democratic Republic of Congo (Bentley et al. 1999) and in Pakistan (Pradeilles et al. 2017).

Among respondents who spoke about health within the household, some women explain that men undertake more physical labor and therefore, men's health should be prioritized. Baadarika, from Odisha, explains why prioritizing her husband's and male in-laws' health above her own is sensible. She says, "We give priority to the male members of the household to be taken to hospital because if they stay free from disease, they will look after us. When female members are ill, most stay at home and take home remedies or procure medicines locally." Some women sold the assets they had or dissolved savings to secure medical treatment for their husbands, but not for their own ailments. 
Eashita, from Odisha, explains that she had borrowed money and sold gold jewelry to treat her husband.

\section{Alcohol consumption}

Heavy alcohol use by a woman's husband can impact household members' nutrition in two ways. First, there is a loss of income or assets when a husband either sells assets for money for alcohol or is unable to work. Women with husbands who drink heavily report seeking work to make up for these losses, but most earn less than their partners, putting the household at risk of hunger. If a woman needs to seek calorically intensive work, such as collecting leaves from the forest, she may need to increase her food intake to replace the expanded caloric use but may not be able to. Even after becoming the main earners, many women continue to abide by inequitable norms, often because of links between alcohol use and violence. Second, there are health and wellbeing effects of living with heavy drinker, including the potential increased risk of IPV. In Odisha, many respondents reported that their spouses' alcohol consumption was excessive and regular, particularly in hilly areas. Bangladesh is a dry country, and no one in our Bangladesh sample reported alcohol as a constraint to her or her families' nutritional status although IPV rates are extremely high.

A partner's heavy alcohol use can influence both access to adequate health and food. One Odia interviewee, Aalaya explained, “[once], I suffered from a fever for 15 days. We had no money to go to the medical center. I suffered silently as I am a woman." She works to support her family. Her husband no longer works because of dependence on alcohol. He suffers from high blood pressure and she takes out loans to support his treatment. She explains that, although she has rheumatism, she does not go to the hospital for her own treatment and relies on local herbs. She does not risk upsetting her husband because "He will start a quarrel for no reason. I remain silent." Thus, Aalaya, 
like other Odia and Bangladeshi respondents, conceals her health-related problems, hoping the problem will go away, rather than voice her discomfort.

Rabani, from the hilly areas of Odisha, explains that her husband's excessive alcohol use means he works only sporadically, impoverishing her family. Her daily workload has increased with his alcohol use and currently includes trekking to the forest to collect leaves for plates, stitching the plates, and the domestic work of cooking, cleaning, and taking care of their children. Stitching and selling leaf plates is an important economic opportunity for Odia women who have access to forest common pool resources, and especially for women who are members of self-help groups and for women whose husbands consume alcohol. About her husband's role in the family, Rabani states, "He helps once in a hundred days... I always do all of the work. ... In situations [when I am ill] I usually stay laying down and when I ask for help from my husband, he rarely responds and then I only have to do all the work again. ... My husband is a drinker. So how could he be able to take care of me?"

Yadhana, also from the hilly areas of Odisha has become the primary breadwinner for her two school-aged children and her husband. She cultivates turmeric, stitches leaf plates, and seeks wage labor. Loss of her husband's earnings means that money is tight. Often, she is unable to care for her family as well as she would like. She explains, "My husband drinks so much alcohol. He never brings home food when our greens, lentils, and [other] vegetables have been finished. He quarrels a lot with me and if I say something to him then it creates disturbances in our home. When I conceived my older son, after six months, he [started] to drink a lot of alcohol.... [Now] I work for wages making leaf plates... I earn money for clothes and medicine for our children by selling the leaf plates. My husband does not give me money. He doesn't know how to work, so where he will get money from?" 
Finally, some women report that their husbands' alcohol use increases the likelihood of IPV.10 Raadhi also from the hilly areas of Odisha, explains how tragedy led to her husband's heavy alcohol use, which she feels is the main reason for their impoverishment and a factor contributing to her husband's violence. She says, "It was an unbearable sorrow that my son died at the age of 6 years. Out of grief due to death of my son, I could not go to work and stayed in the house, mourning. My husband became drunkard and started beating me often. My husband could not go to work. I struggled, cultivated my land, ... and managed the family. He sold all of our belonging to consume wine. Even our bullock." Raadhi is now both the main earner and the main decision-maker regarding food and nutrition in her household. Yet, she continues to serve her husband first and more food; she eats least and last because "Otherwise, he will start quarreling." While alcohol compounds the impact of poverty on nutrition, it seems likely that given the links between IPV and alcohol use, there is the strong possibility of effects of alcohol use on women's nutrition other than through poverty alone. This suggests interventions that focus on poverty alleviation without addressing alcohol use will not be as effective. The link between IPV and excessive alcohol use is discussed further below.

\section{Intimate partner violence}

Intimate partner violence (IPV) between a woman and her partner also shapes women's decisions about food and nutrition.11 In Odisha, many women link IPV to their husbands' alcohol consumption; in Bangladesh, many women connect it to poverty, stress, and hunger, although IPV is

\footnotetext{
10 The link between alcohol use and IPV has been documented elsewhere (see Koenig et al. 2003; Kyriacou et al. (1999) documents increased risk of injury from IPV due to a partner's alcohol use).

${ }^{11}$ During our conversations with community researchers, the centrality of domestic violence in women's lives, especially regarding food-related decisions, became clear. We aimed to follow best practice on ethical research of intimate partner violence as laid out by Ellsberg and Heise (2002), given the context and resources available in rural Bangladesh and rural Odisha. See Lentz (2018) for more information on our research protocols.
} 
not limited to impoverished individuals (Schuler 2008; Lentz 2018). IPV is widespread; a study in Bangladesh found that 61 percent of women experience IPV during their lives (Fakir et al. 2016). A systematic review of quantitative studies on domestic violence in India found the median rate of domestic violence occurring to a woman in her lifetime is 41 percent (Kalokhe et al. 2017). Children whose mothers experience IPV are likelier to have worse nutritional outcomes in both the short term and long term (Yount et al. 2011).12 Bellows et al. (2015) have argued gender-based violence contributes to women's food and nutrition insecurity in Georgia and South Africa.

In both Bangladesh and Odisha, several respondents who eat last and least explain that abiding food norms is a way to avoid IPV or quarrels. An interviewer asks Aamodini, from Odisha, "Why do you serve your husband] first?" She succinctly explains, "If he doesn't eat first then he may beat me." Saarya, a married Odia woman who lives with her husband, a grown son, a daughter-in-law and grandchildren, described how she avoided violence. She explains "My husband is a drunkard. He never gives money [to me for food]. I serve food to my husband first ... What is left over we [my daughter-in-law and I] eat. Otherwise we do not. ... [My husband] will start quarrel for no cause. I will remain silent. ... My earnings are very low, not sufficient for sustenance. My husband sometimes snatches away my money to buy liquor." Saarya is a primary breadwinner, and in charge of feeding a large family. Yet, when there is not enough food, she and her daughter-in-law remain silent, even going hungry rather than risk violence from Saarya's husband. Earning an income, while often considered empowering (Kabeer 2011), is not enough to counter her husband's violence nor for her to have adequate amount to eat.

12 There is less research on the role of violence on women's own nutritional and food security status, particularly for women who are not of child bearing age (see Yount et al. 2011; Bellows et al. 2015; Lentz 2018). 
Several women with violent spouses describe how experience of and or fear of violence exacerbates health and nutritional disparities in their households. In Bangladesh, Shireen finds a way to support her husband's health, but has not receive adequate care when she was ill. Her husband recently had cholera. To fund his treatment, she sold her poultry and borrowed from neighbors and her father, raising six and a half thousand taka, (about $\$ 80$ in 2016) In response to the question: "Do you think he would spend this much for you if you were suffering with the same?" Shireen states, "I don't think he would do that. I have been suffering from severe back pain for last couple of days without any treatment." Her father offered to share the treatment costs with her, but having recently sold her poultry to treat her husband's cholera, combined with her husband selling her cow last year without consulting her, she cannot afford to go. She is also wary about asking her husband directly for funds because he was the one who hurt her. He hit her with a stick, which made her faint and fall, injuring her back.

Some women explain that when they ask for help, their requests may be ignored or may put themselves at risk of violence. Zankrut, in Odisha, experiences both of these. "One day I fell sick while I was pregnant. I asked my husband to fetch water from well as there was no tube well in my village. My husband refused to bring water and told me, 'Why should I bring water? You are a woman. It is your duty to fetch water and cook.' He refused to fetch our water. With great difficulty, I fetched water, cooked, and served him food. ... [My husband] was not regularly working. When I asked him to find day labor work, he started to quarrel with me and beat me. I had to go to our neighbors' to escape from beating." Zankrut adds that she returned to wage labor with her threeweek old child, because her husband was not working.

Similarly, Sadia, a Bangladeshi woman who now lives in a nuclear family, describes her earlier married life when she resided in a joint household with her in-laws. When she was living with her 
in-laws, she was expected to eat last and was served only the leftovers. "[My husband and in-laws] had the privilege to eat first. After all were finished, the leftover pieces were given to me. At times, I had to return my mother's house due to hunger." When she confronted her husband about her hunger and asked him to work as a day laborer to earn more money, he beat her. Thus, violating food norms exposed her to violence.

Zaaei, from Odisha, stitches leaf plates to earn money for food for her four children, for medical expenses, and for schooling. She also does all of the domestic work. She wakes daily at three A.M. to walk 3 plus kilometers to a mountain where she collects leaves. Her husband is a heavy drinker who rarely contributes to the household. Zaaei explains “My husband doesn't do any work. He drinks alcohol regularly, and when I say, "Why do you drink so much alcohol when you know that we don't have sufficient food in our home? How can we support our children for their study? We remain illiterate but our children should be literate. They should not hesitate like us or feel ashamed while talking with people." He argues back, saying, "I am not under you and don't want to listen you." He is also violent, and she does not push against food allocation norms. She serves her husband food first and then her children. She says, "If anything is left after serving my children, only then do I eat. Otherwise, I remain hungry." In order to prioritize her children's education, Zaaei often goes to bed hungry.

There are several implications that we can draw from cases such as Zaaei's. First, she is willing to be hungry in order to send her children to school, suggesting that her own nutritional status is not her first priority. Second, her husband's drinking led to Zaaei's expansion of activities to include earning income to support her family, but her earnings have not translated to her upending norms about food allocation. Earning income may have expanded Zaaei's agency in some areas of her life, but her ability to eat with the family remains constrained by the threat of violence. Thus, her agency 
remains constrained or burdened (Lentz 2018). This suggests increasing opportunities for women to earn money may not be enough to improve their nutritional outcomes and that expanding women's agency and empowerment in one domain may not be adequate to change relations in other domains (Kabeer 1999). Third, the discomfort she and her husband feel when interacting with educated people suggests that both she and her husband are disempowered within the community, albeit to different degrees.

These examples show that the dynamics among IPV, excessive alcohol use and undernutrition are complex. A husband's heavy alcohol use can be impoverishing and contribute to stress. It can also contribute to violence. The threat of violence can shape women's decisions about who receives enough food in the home or when to seek healthcare and of what quality. When a woman regularly chooses hunger or fails to seek healthcare to avoid or limit the effects of a partner's heavy alcohol use or IPV, her long-term nutritional status may deteriorate. If she is "successful" at avoiding IPV, survey questions asking a woman about her experience of violence (rather than the threat of violence) will mask its linkages to nutrition. A measure of domestic violence that captures exposure does not capture the nutritional costs of those who decrease intake to avoid violence. Further, women may also trade off high quality healthcare and wellbeing to avoid or limit the effects of these factors. In our data, while women from impoverished households more commonly describe trading off nutritional wellbeing to avoid or limit the effects of IPV and a partner's alcohol use, they are not limited to impoverished households.

\section{Deviating from local norms}

Many women report more difficulty in accessing adequate food and health earlier in their marriages, particularly when residing with their in-laws. As women - and their children - grow older, they are more likely to eat with the family. Thus, intrahousehold provisioning of food and 
health vary, within the same communities and even within the same households (Kandiyoti 1989). Several respondents explain that support from family members, civil society, having adult children in the home, being older, or a wage earner allows them to experience more equitable access to food and health within their households.

Kabeer (2011) shows that self-help groups, including our Bangladesh partner, Nijera Kori, can support women's empowerment, especially as it relates to public engagement. Being empowered in the public sphere can also influence intrahousehold norms. A few Odia respondents report taking a strong anti-alcohol stance and used civil society membership to collectively advocate for more restrictions on alcohol. In one case, Sahaja, a member of a local civil society organization, described how when she, representing her civil society, approached the state chief minister to stop the production and sale of alcohol in her local area. He agreed, although their efforts to ban alcohol were undone when the next government came to power.

Several older respondents, some of whom are members of local self-help groups, report they now eat with their families. Yati, a member of an Odia self-help group, and mother of three adolescent children, explains "We eat together on the days that all are present at home, and, if my husband is late, then I keep his share on the shelf. Then I call for the children [and the children and I eat together]." Similarly, Barsha, a member of Nijera Kori residing with her husband and adult daughter describes how "because of the Shomity [Nijera Kori Self Help Committee]", she and her husband now meal plan together and eat together. Thus, norms around food allocation can become "denaturalized" as women get older or as they gain exposure to new ideas, such as from civil society membership (Kabeer 2011). 
Access to high quality health services depends not only on norms, as mediated by age and civil society membership, but also by access to health-related social protection schemes and familial support. One elderly Odia woman, Zyanna, who lives near public services, explains that her health insurance card defrayed some of the costs of a recent illness both she and her husband had. Her youngest daughter also fell ill and all three received the same treatment. Her health insurance card, while helpful, did not cover all of her costs and her family now has 22,000 rupees of medical-related debt (about \$340). Her brothers, who live nearby and own land, have helped her cover previous medical expenses. Having access to familial support and health insurance enables her to seek higher quality healthcare. Her status as an older, married woman also makes it easier for her to access higher quality healthcare relative to younger or widowed women (Cain et al. 1979).

\section{Discussion and Conclusion}

Our research aims to expand our understanding of what factors contribute to nutritional outcomes of women and their families in rural Bangladesh and rural Odisha. A key finding for nutritionrelated research is that many women reported being unable to access the same quality of care and diets as the rest of their households. As a result, their nutritional status may be worse relative to household members who are prioritized, such as husbands, in-laws, and children. This indicates the value of measuring the nutritional status of all individuals within a household. Measuring nutritional and health outcomes of only a subset of family members (e.g., children under age five) or only at the household level risks overlooking undernutrition of other household members, perhaps especially women (D’Souza and Tandon 2018). Similarly, asking questions about the location and quality of various health services, or even if someone within the household has used these services, as is common in many quantitative surveys, will fail to capture that women tend to wait longer to seek care, and tend to seek lower quality care than their husbands. A better understanding of the dynamics and allocations within households can help us to isolate nutritional differences within 
households, and potentially guide interventions that aim to address intermediate and basic drivers of undernutrition.

The rationales for inequitable access to healthcare and food based on gender vary across households. By interrogating the ways by which household members make decisions about nutrition, qualitative work can contribute to undernutrition research by identifying factors not yet regularly included in quantitative studies and surveys of undernutrition in South Asia. ${ }^{13}$ Some respondents explain that they eat least and last or seek low quality healthcare because they follow norms that prioritize men. Other respondents report following inequitable norms to avoid conflict with a violent and/or an intoxicated spouse. Our respondents report that underlying social issues of a husband's alcohol use and IPV, while seemingly far removed from drives of undernutrition, have nutritional consequences for and impose vulnerabilities on them. As shown elsewhere (e.g., Kabeer 2011), age, civil society membership, and access to social and familial support can enable women and their families to challenge such norms. Our cases also show that to earn one's own income does not automatically guarantee the ability to influence norms. Thus, a second implication of our research is that addressing underlying social issues may help support women who want to challenge inequitable norms around food and health provisioning.

Finally, our findings show that a gendered perspective can identify limitations and possibilities that specific household members face in achieving nutrition. By taking seriously the issues that women themselves raise as important, we foreground two rarely considered but potentially important factors structuring women's abilities to achieve the nutritional status they would like. Such an emicapproach identifies the barriers faced that are not normally included in quantitative research. An

\footnotetext{
${ }^{13}$ When surveys do include these topics, the questions may not fully capture the effects of IPV and alcohol use on nutritional status. For example, many Demographic and Health Surveys (DHS) ask respondents about experiencing or attitudes about IPV. Yet, the threat of IPV may have as great an effect on nutrition as the experience of it (Lentz 2018).
} 
important avenue for future research is the better measurement of social factors that appear to influence intrahousehold nutrition. Without attending to the specific barriers faced by women, Odisha's and Bangladesh's recent advances in addressing child nutrition risk failing to reach all household members. 


\section{References}

Alderman, H. Chiappori, P.A., Haddad, L., Hoddinott, J., and Kanbur, R. 1995. "Unitary versus collective models of the household: Is it time to shift the burden of proof?" World Bank Research Observer. Feb: 10(1): 1-19.

Avula, R., Raykar, N., Menon, P., and Laximinarayan. 2016. "Reducing stunting in India: what investments are needed?" Maternal and Child Nutrition. May; 12 (Suppl 1): 249-252.

Bellows, A. C., Lemke, S., Jenderedjian, A., and Scherbaum, V. (2015) "Violence as an underrecognized barrier to women's realization of their right to adequate food and nutrition: case studies from Georgia and South Africa." Violence Against Women. 21(10): 1194-1217.

Bentley, G. et al. 1999. "Women's strategies to alleviate nutritional stress in a rural African society." Social Science and Medicine. 48: 149-162.

Bezner Kerr, R., Dakshioni, L., Shumba, L., Msachi, R., and Chirwa, M. 2008. "We grandmothers know plenty": Breastfeeding, complementary feeding, and the multifaceted roles of grandmothers in Malawi." Social Science and Medicine. 66(5): 1095-1105.

Cain, M., Khanam S.R., and Nahar, S. 1979. "Class, Patriarchy, and Women's Work in Bangladesh.” Population and Development Review. 5(3):405-438.

Coffey, D., 2015. Prepregnancy body mass and weight gain during pregnancy in India and subSaharan Africa. Proceedings of the National Academy of Sciences, 112(11), pp.3302-3307.

Cons, J. and Paprocki, K (2010) 'Contested credit landscapes: microcredit, self-help, and selfdetermination in rural Bangladesh.' Third World Quarterly. 31(4): 637-654.

Cunningham, K., Ruel, M., Ferguson, E., and Uauy, R. 2015. "Women's empowerment and child nutritional status in South Asia: A synthesis of the literature." Maternal \& Child Nutrition. 11(1): 119.

D'Souza, A. and Tandon S. 2018. "Intra-household Nutritional Inequities in Rural Bangladesh." Economic Development and Cultural Change. Online first. Accessed May 14, 2018.

Ellsberg, M. and Heise, L. 2002. "Bearing witness: ethics in domestic violence research." The Lancet. 359:1599-1604.

Fakir, A. M. S., Anjum, A., Bushra, F., and Nawar, N. 2016. "The endogeneity of domestic violence: Understanding empowerment through autonomy." Journal of Development Perspectives. 2: 34-42.

Pradeilles, R. et al. 2017. "The relationships between crop-related agricultural workload and maternal and infant nutritional status in rural Pakistan."ANH Scientific Symposium and Academy Week: 2017. https://anh-academy.org/sites/default/files/Haris\%20Gazdar.pdf Accessed May 24, 2018.

Gilllespie, S., van den Bold, M., and the Stories of Change Study Team. 2017. "Stories of Change in nutrition: An overview." Global Food Security. 13: 1-11. 
Haddad L, and Kanbur R. 1990. "How serious is the neglect of intra-household inequality?" Econ Journal. 100:866-81.

Harris-Fry, H., Shrestha, N., Costello, A., and Saville, N. 2017. "Determinants of intra-household food allocation between adults in South Asia - a systematic review." International Journal for Equity in Health. 16: 107- 128.

Harriss-White B. 1991. "Chapter 10. The Intrafamily Distribution of Hunger in South Asia." In: Dreze J, Sen A, editors. The Political Economy of Hunger: Volume 1: Entitlement and Well-being. Oxford: Clarendon; 1991.

Headey, D. 2012. "Developmental Drivers of Nutritional Change: A cross-country analysis." World Development. 42: 76-88.

Headey, D. et al. 2015. "The Other Asian Enigma: Explaining the Rapid Reduction of Undernutrition in Bangladesh." World Development. 66: 749-761.

Headey, D. Hoddinott, J., and Park, S. 2017. "Accounting for nutritional changes in six success stories: A regression-decomposition approach.” Global Food Security. 13: 12-20.

Kabeer, N. 2011. "Between Affiliation and Autonomy: Navigating Pathways of Women's Empowerment and Gender Justice in Rural Bangladesh. Development and Change. 49(2): 499-528.

Kabeer, N. 2017. “Economic Pathways to Women's Empowerment and Active Citizenship: what does the evidence from Bangladesh tell us?" The Journal of Development Studies. 53(5): 649-663.

Kalokhe, A., et al. (2017). "Domestic violence against women in India: A systematic review of a decade of quantitative studies." Global Public Health. 12(4):498-513.

Kandiyoti, D. 1988. "Bargaining with patriarchy." Gender and Society. 2(3): 274-290.

Kavle, J.A. and Landry, M. 2017. "Addressing barriers to maternal nutrition in low- and middleincome countries: A review of the evidence and programme implications." Maternal and Child Nutrition. Pp1-13.

Khandker, S. R., Khalily, M.A. B., and Samad, H.A. 2012. "Seasonal Hunger and its mitigation in northwest Bangladesh.” The Journal of Development Studies. 48:12. Pp. 1750-1764.

Koenig, M. A. et al. (2003) "Domestic violence in rural Uganda: Evidence from a community based study." Bulletin of the World Health Organization. 81(1): 53-60.

Kohli, N. et al. 2017. "Reprint of 'What will it take to accelerate improvements in nutrition outcomes in Odisha? Leaning from the past." Global Food Security. 13:38-48.

Kyriacou, D. et al. (1999) "Risk factors for injury to women from domestic violence." New England Journal of Medicine. 341:1892-1898

Lentz, E. (2018) 'Complicating narratives of food and nutrition insecurity: domestic violence in rural Bangladesh.' World Development. April. 104:217-280. 
Marcoux, A. 2002. "Sex Differentials in Undernutrition: A look at the evidence." Population and Development Review. June. 28(2): 275-284.

Munro, J., and McIntyre, L. 2014. “'Why should I feed her less?': Challenging assumptions on daughter discrimination in the food provisioning values of ultrapoor Bangladeshi female heads of household." Women's Studies International Forum. 45: 1-9.

Narayanan S., Lentz, E., Fontana, M., and Kulkarni B. Under review. "Rural Women's Empowerment in Nutrition: A Framework Linking Food, Health and Institutions"

Malapit, H.J.L., S. Kadiyala, A.R. Quisumbing, K. Cunningham, and P. Tyagi (2015) 'Women's Empowerment Mitigates the Negative Effects of Low Production Diversity on Maternal and Child Nutrition in Nepal.' Journal of Development Studies. 51:8, 1097-1123.

Nisbett, N. et al. 2017. "Community-level perception of drivers of change in nutrition: Evidence from South Asia and sub-Saharan Africa." Global Food Security. 13: 74-82.

Pinstrup-Andersen, P. (2014) 'Chapter 2: Food Systems and Human Nutrition: Relationships and policy interventions.' Eds. B. Thompson and L. Amoroso in Improving Diets and Nutrition: Food Based Approaches. Rome: Food and Agriculture Organization.

Pratley, P. 2016. 'Associations between quantitative measures of women's empowerment and access to care and health status of mothers and their children: A systematic review of evidence from the developing world.' Social Science and Medicine. 169: 119-131.

Raj, A., McDougal, L. and Silverman, J. 2015. “Gendered Effects of Siblings on Child Malnutrition in South Asia: Cross-sectional analysis of Demographic and Health Surveys from Bangladesh, India, and Nepal." Maternal Child Health Journal. 19:217-226.

Rampal, P and Narayanan, S. 2018. "Mothers and Children: Discordance in nutritional status" Mimeograph from Indira Gandhi Institute for Development Research.

Schuler, S. R., Bates, L.M., and Islam, F. 2008. "Women's Rights, Domestic Violence and Recourse Seeking in Rural Bangladesh." Violence Against Women. 14(3):326-345.

Sohoni, NK. 1998. "Girls and International Development." In N. Stromquist, ed. Women in the third world: an encyclopedia of contemporary issues. Garland Publishing: New York.

UNICEF (1990) 'Strategy for Improved Nutrition of Children and Women in Developing Countries.' Policy Review Paper E/ICEF/1990/1.6, JC 27 UNICEF /WHO. UNICEF: New York.

UNICEF (2018) 'Training: UNICEF Conceptual Framework.' P4. Accessed 21 May 2018. http://unicef.org/nutrition/training/2.5/4.html

Yount, K., DiGirolamo, A., and Ramakrishnan, U. 2011. "Impacts of domestic violence on child growth and nutrition: A conceptual review of the pathways of influence." Social Science \& Medicine. 72:1534-1554. 


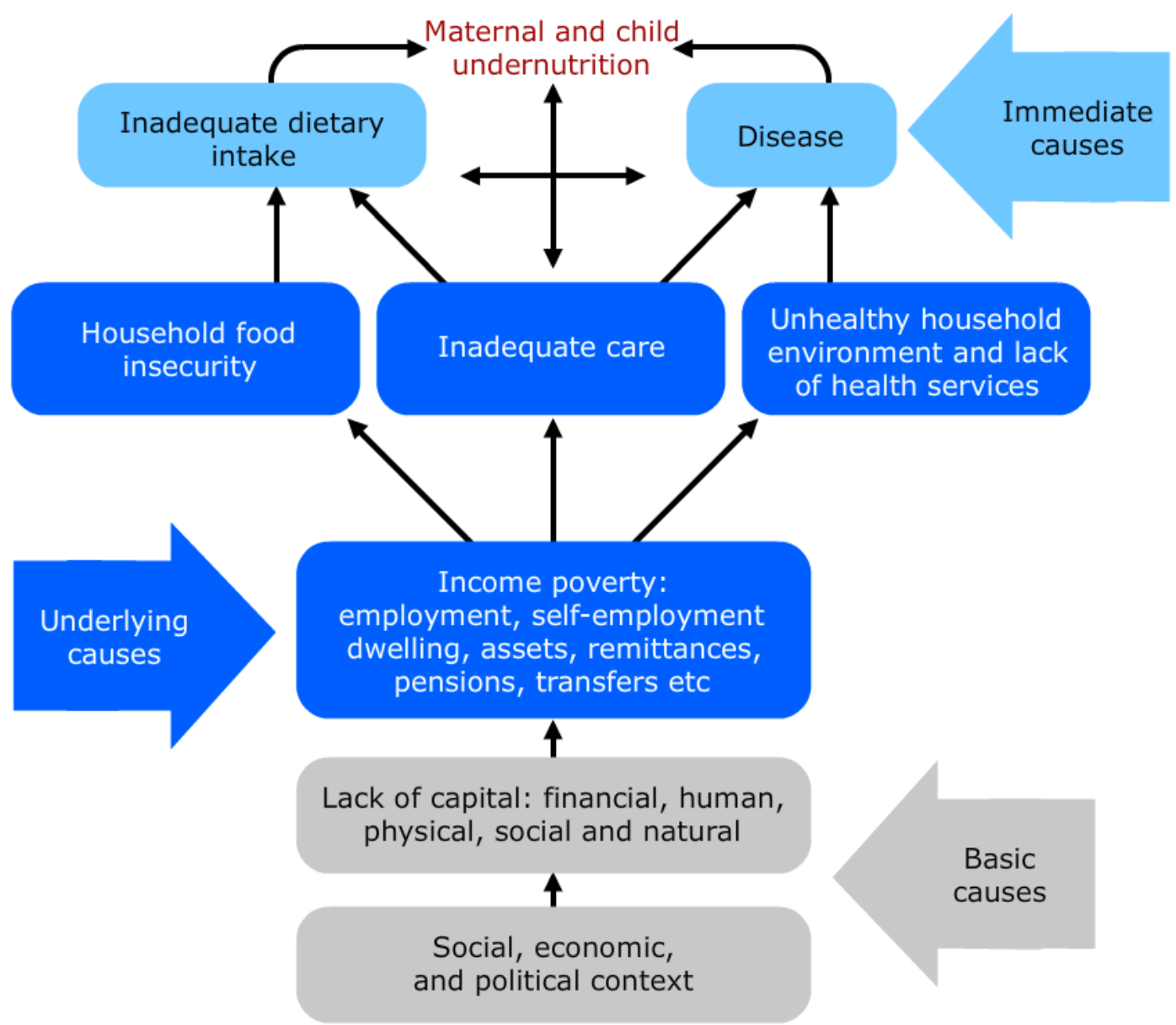

Figure 1. UNICEF's Conceptual Framework (2018) 